\title{
O Estado de Suspensão na aprendizagem histórica: a força estética do conhecimento histórico na instauração de um momento sublime de consciência histórica
}

\author{
The State of Suspension in the historical learning: \\ Aesthetic force of historical knowledge in establishing \\ a sublime moment of historical consciousness
}

Rafael Saddi*

\section{Resumo}

O presente artigo tem o objetivo de conceituar o Estado de Suspensão como momento radical da aprendizagem histórica. Trata-se do estado instaurado no momento em que a força estética interpeladora de um conhecimento provoca, justamente por atingir, de algum modo, o âmago do indivíduo, a suspensão das atribuições de sentido anteriormente em vigor. Para a compreensão desta definição e de sua importância, o artigo está dividido em três momentos. O primeiro trata da alteração que a influência da Didática da História alemã produz na função dos professores; o segundo analisa a atuação fundamental dos elementos estéticos da narrativa histórica para a produção de sentido histórico, e o terceiro descreve e define este novo conceito de Estado de Suspensão como momento radical e sublime da consciência histórica.

Palavras-chave: estética; Didática da História; consciência histórica.

\section{Abstract}

This article aims to conceptualize the State of Suspension as a radical moment of historical learning. This is the state established when aesthetic power of knowledge causes, precisely by reaching in some way, the individual core, the suspension of sense attributions previously valid. To understand this definition and its importance, the article is divided in three stages. The first deals with the influence of didactics of German history and the changes it causes in teachers' tasks; the second analyzes the importance of the aesthetic elements of historical narrative for the production of historical sense, and the third defines this new concept, State of Suspension, as radical and sublime moment of historical consciousness.

Keywords: aesthetics; History Didactics; historical consciousness.

\footnotetext{
* Doutor em História. Professor adjunto da Universidade Federal de Goiás (UFG). Goiânia, GO, Brasil.rafaelsaddiufg@gmail.com
} 
Existe um momento, que pode ocorrer em uma sala de aula ou fora dela, em que uma narrativa histórica escrita ou oral, um relato de época, uma imagem, um filme, uma reflexão teórica, um gesto, uma música ou um texto literário do passado ou referente a ele produz uma suspensão dos elementos estruturais que ordenam o conjunto da percepção que temos do nosso mundo e de nós mesmos.

Nesse momento, a montanha de referenciais com os quais interpretamos e fornecemos sentido à existência desmorona; a régua de valores com a qual medimos, de modo exato, o certo e o errado, o Bem e o Mal, o importante e o irrelevante, se rompe e a amplitude do tempo e do espaço em que nos localizamos reinantes se alargam na mesma proporção em que vamos nos encolhendo como uma vela acesa. Em uma imagem, o teto simbólico que nos abriga e nos protege desaba sobre a nossa própria cabeça e, boquiabertos, pressentimos a existência de um universo inteiro de demônios ameaçadores que poderiam passar uma vida inteira errante sem serem libertados.

Esse estado, em que já me vi entrar inúmeras vezes, como estudioso ou ainda quando aluno, e ao qual já pude presenciar, como professor, o ingresso de inúmeros jovens, é, por excelência, um momento fundamental da aprendizagem. Ele permanece, porém, não conceituado, não classificado, não elevado à condição de objeto de reflexão.

Podemos dizer que tal momento extraordinário ocorre não simplesmente na aprendizagem especificamente histórica, mas existe como potência no aprendizado de todo e qualquer conhecimento humano. Nosso objetivo, porém, aqui é conceituar esse estado geral a partir da aprendizagem peculiar da História. Nos interessa, sobretudo, defini-lo como movimento radical da consciência histórica.

O presente artigo é, portanto, teórico. Ele parte das categorias centrais da Didática da História Alemã e investiga as contribuições que a chamada Estética Filosófica Moderna pode fornecer para a percepção de um momento específico da consciência histórica e do aprendizado histórico.

Não negamos a possibilidade de verificação, através de pesquisa empírica, do conceito aqui formulado. Entretanto, a própria definição de Estado de Suspensão como um estado estético limita o nosso objeto ao âmbito do intuitivo. A ausência de palavras que esse estado provoca dificulta, quando não impossibilita, a sua percepção através de exercícios de cognição, entrevistas e 
questionários. Sua percepção é, portanto, também intuitiva, derivada de uma apropriação da estética filosófica para a reflexão sobre momentos de aprendizagem vivenciados. Em outras palavras, todo e qualquer professor, aluno ou ex-aluno será capaz de reconhecer, na definição e descrição aqui fornecidas, a existência de tal estado se e, contanto que, o tenha já vivenciado. Para uma abordagem estritamente filosófica, esse único critério empírico nos parece suficiente.

Para alcançarmos essa percepção do Estado de Suspensão como momento radical da consciência histórica nos processos de aprendizagem, este texto está divido em três partes. A primeira tem o objetivo de apresentar o modo como, a partir da influência da Didática da História alemã, o professor passa a ter uma nova tarefa: a de propiciar que o conhecimento histórico escolar produza sentido para a vida dos alunos. Teremos, nesta primeira parte, um objetivo específico para o ensino de história em sala de aula.

Tal objetivo, porém, não pode ser alcançado sem se levar em conta a relevância comunicativa do conhecimento histórico. O segundo momento pretende, assim, analisar, a partir de Jörn Rüsen, os elementos estéticos inerentes de toda e qualquer história, elementos sem os quais esse conhecimento histórico significativo não se tornaria possível.

A terceira e última parte tratará mais especificamente do conceito de Estado de Suspensão, apresentando uma descrição das características estéticas inerentes a ele a partir do diálogo com a estética filosófica moderna, com destaque para a metafísica do Belo e do Sublime produzida por Schopenhauer.

\section{ENSINAR HistóRIA COM SENTIDO PARA A VIDA}

A partir da primeira década deste século, a área tradicionalmente conhecida como ensino de história no Brasil passou a sofrer grande influência da literatura alemã. A partir especialmente das traduções das obras de Jörn Rüsen (2001, 2006, 2007, 2007a, 2012, 2014 e 2015), mas também de textos de Klaus Bergmann (1990) e de Bodo von Borries (2012), e do acesso na língua original de autores como Jeismann e Pandel, diferentes pesquisadores brasileiros se debruçaram sobre novos temas, conceitos e objetos de pesquisa anteriormente não conhecidos no campo do ensino de história brasileiro. 
Além de textos programáticos, ${ }^{1}$ encontra-se, de modo ainda mais numeroso, um conjunto de teses de doutorado e de dissertações de mestrado que, se não estão em completo acordo com a definição da Geschichtsdidaktik, ao menos se utilizam de conceitos e categorias formulados por ela.

O que nos interessa, aqui, entretanto, é identificar o fato de que a influência da Geschichtsdidaktik alterou não só a qualidade da reflexão didático-histórica e o campo de interesse dos pesquisadores brasileiros, mas, também, produziu um novo desafio para o professor de História em sua práxis em sala de aula.

Esse desafio, apresentado por inúmeros pesquisadores, carrega, como percebeu Barom (2012), um pressuposto: o de que a consciência histórica é passível de ser transformada/formatada no interior do ambiente escolar.

Deste modo, a consciência histórica pode ser, na escola, por meio do trabalho educativo, "formada (Bonifácio, 2005, p.198), produzida (Medeiros, 2005, p.1), cultivada (Furmann, 2006, p.71), elaborada (Sobanski, 2008, p.24), desenvolvida (Castex, 2008, p.27), ampliada (Fernandes, 2007, p.55)" (Barom, 2012, p.76). A função do ensino de história passa a ser, assim, “a colaboração no desenvolvimento da consciência histórica" dos alunos. "E esta colaboração seria passível de ser administrada e conduzida pelo processo educativo" (ibidem, p.76).

Poderíamos dizer, entretanto, que essa função do ensino de história aparece somente nas palavras dos pesquisadores, não sendo ainda um desafio incorporado pelo próprio professor de História. Tal percepção seria, entretanto, falaciosa, primeiro porque grande parte dos pesquisadores são também professores. Em segundo lugar, porque temos ao menos uma pesquisa empírica no Brasil que evidenciou o modo como alguns professores de história do ensino básico pensam a sua práxis em sala de aula a partir de um desafio concreto que lhes foi despertado pelas reflexões teóricas próprias da literatura alemã.

Trata-se, aqui, da dissertação de mestrado de Thiago Oliveira (2012), sob a orientação da professora Maria Auxiliadora Schmidt, que investigou o modo como professores de História da cidade de Araucária, no Paraná, que já haviam tido acesso aos debates teóricos sobre consciência histórica, refletiam sobre a sua própria práxis docente. 
Uma das constatações de Oliveira (2012, p.128) nessa pesquisa, que nos interessa profundamente neste artigo, é a de que "uma vez que os professores entrevistados já tomaram, em alguma medida, conhecimento da teoria da consciência histórica, suas falas em relação ao ensino de história permitem a composição da categoria sentido".

Trata-se, assim, de dizer que os professores investigados entendiam que, em suas aulas, deveriam tornar a História um conhecimento que fizesse sentido, isto é, que fosse útil para a orientação temporal da vida dos seus alunos. Tal é o caso do professor Valdeci, que em entrevista a Oliveira afirmou:

Quer dizer ele deu Sentido. Aquilo está dando sentido para a vida dele, mas não em um sentido apenas para automaticamente ir em uma avaliação e tirar nota. Não, não é isso. É um sentido, de sentido da História que faz com que ele compreenda o mundo que ele vive, as relações que ele vive, relações dialéticas entre as coisas que acontece, e que ele vive. (Valdeci, em Oliveira, 2012, p.129)

Essa preocupação do professor de história, influenciado pela teoria alemã, em tornar a história, na sala de aula, produtora de sentido para a vida, está sustentada, teoricamente, pela inserção existencial da história na vida humana.

Para Rüsen (2001), o ponto de partida da ciência histórica, mas também de toda e qualquer consciência histórica, são os interesses ou carências de orientação temporal dos seres humanos na vida prática. "Trata-se do interesse que os homens têm - de modo a poder viver - de orientar-se no fluxo do tempo, de assenhorar-se do passado, pelo conhecimento, no presente" (Rüsen, 2001, p.30).

Essas carências de orientação são carências de produção de sentido temporal. Não se trata necessariamente de carências de conhecimento científico, mas da necessidade de interpretação da experiência humana no tempo de modo a produzir sentido necessário para o agir. Em outros termos, não permitir que as próprias intenções sejam levadas ao absurdo no tempo.

Nesse sentido, o ponto de partida clássico da History Education, ${ }^{3}$ o de investigação das ideias históricas prévias dos alunos, não necessariamente implica o mesmo ponto de partida da Geschichtsdidaktik. Partir das carências de orientação temporal dos alunos é diferente de partir de suas ideias históricas prévias. Isso porque tais ideias, ou em outros termos, os conceitos substantivos e epistemológicos da história, não são necessariamente interesses cognitivos 
ou interesses de produção de sentido. Suas formulações não são produzidas a partir da práxis da vida (lebenspraxis), de onde surgem as carências de orientação temporal, mas do interesse do professor em conhecer o modo como os alunos entendem determinados conceitos da História.

A proposta de Oliveira e Schmidt (2014), ao contrário, é a de justamente formular um modo de ensinar história tendo como ponto de partida a práxis da vida dos alunos. Foi justamente na observação da práxis docente de dois professores de História que esses autores detectaram a possibilidade desse tipo de ensino:

um dos professores entrevistados organizou suas aulas de acordo com elementos que havia percebido entre as falas dos alunos. Basicamente, a cidade em que ele lecionava tinha recebido um grande número de migrantes trabalhadores de vários lugares diferentes do país. O impacto social na cidade gerou, segundo o professor, um enunciado linguístico que representava uma forma de preconceito contra esses trabalhadores. Ele elaborou um trabalho com a História a partir da perspectiva da exclusão. De acordo com esse professor a aprendizagem da História poderia proporcionar uma formação histórica como intervenção para contrapor o preconceito dos alunos. (Oliveira; Schmidt, 2014, p.190)

O professor tomou como ponto de partida da organização do conhecimento histórico e das aulas de História um elemento significativo da práxis dos alunos: a existência, entre eles, do preconceito contra os trabalhadores migrantes.

Uma forma semelhante de organizar as aulas de História foi percebida por esses autores na prática de outra professora. Esta, “ao perceber problemas relacionados à desigualdade de gênero, resolveu envolver a perspectiva da História das mulheres em suas aulas" (Oliveira; Schmidt, 2014, p.190).

Nestes dois exemplos, é efetivamente a partir da práxis dos alunos que o professor identifica o conhecimento histórico que ele considera significativo. A preocupação dos professores é a de transformar a consciência histórica dos alunos como forma de transformar o modo como eles se entendem e agem no mundo.

Diferentemente da metodologia clássica da History Education, o objetivo da aula de história não é, aqui, a progressão do conhecimento histórico do aluno tendo como modelo a ciência de referência, mas o refinamento da 
interpretação histórica dos alunos com a finalidade de ampliação da orientação temporal para o agir. Dessa forma, o ponto de partida e de chegada torna-se, de todo modo, a práxis da vida.

Ainda assim, torna-se difícil dizer se a metodologia de ensino que está sendo formulada por Oliveira está efetivamente partindo das carências de orientação temporal dos alunos. Isso porque identificar, na práxis, um conjunto de atitudes e de pensamentos que possam ser ampliados e transformados pelo conhecimento histórico não implica necessariamente que tais alunos sintam interesse ou necessidade vital de produção de orientação com relação a isso.

As carências de orientação temporal são interesses cognitivos. Se falamos em carências de orientação temporal dos alunos estamos falando também de seus interesses por interpretar o passado de modo a poder suprir tais necessidades de orientação. Nos exemplos citados por Oliveira e Schmidt (2014) o que está em questão é o interesse do professor em alterar determinados comportamentos percebidos na práxis dos alunos e não os interesses cognitivos e existenciais dos próprios estudantes.

De todo modo, a metodologia apresentada por esses autores é, em nossa opinião, a melhor proposta que a didática da história no Brasil foi capaz de produzir em termos de proposta metodológica para a produção de uma aula de História vinculada diretamente ao conceito alemão de Consciência Histórica.

Ocorre que, para além da constante dificuldade de um professor acessar as carências de orientação temporal dos seus alunos, até mesmo a sua dificuldade em identificar aquilo que efetivamente são os interesses cognitivos dos alunos pelo conhecimento histórico, as aulas de história, ainda que tomem os elementos da práxis da vida como ponto de partida, correm o risco de fracassar no âmbito da relação comunicativa. É exatamente disso que vamos tratar adiante.

A FORÇA SENSORIAL DA ESTÉTICA NA PRODUÇÃO DA CONSCIÊNCIA HISTÓRICA

Apesar de o interesse cognitivo pelo passado ser o ponto de partida existencial de toda e qualquer história, o professor de História depara, 
constantemente, com o desinteresse dos alunos pelas aulas. Como descreve Jörn Rüsen (2007a, p.30):

No ensino de história, o saber histórico pode vir a ser percebido pelas alunas e pelos alunos como um ramo morto de sua árvore do conhecimento. Aparece, assim, como massa de informações a serem decoradas e repetidas para satisfazer os professores, com o mero objetivo de tirar boas notas. Perde qualquer valor relativo no modo como as crianças e os jovens pensam seu tempo, sua vida e seu mundo. Em momentos de crise, até mesmo professores de história chegam a admitir que muitos dos conteúdos tratados nas aulas possuem esse caráter disfuncional e que dificilmente desempenharão qualquer papel decisivo em situações concretas da vida, posteriormente.

Organizar as aulas de História a partir da práxis do aluno é uma ação fundamental para superar esse caráter disfuncional do saber histórico e torná-lo relevante para o modo como as crianças e os jovens interpretam seu mundo e nele atuam. Tal atitude é, não de modo estrito, mas, sobretudo, uma atitude ética, uma vez que exige do professor a percepção daqueles modos de agir dos alunos que precisam ser transformados. Os elementos éticos que condicionam as escolhas dos professores, entretanto, embora extremamente relevantes, não são os únicos elementos que devem ser considerados.

Uma das percepções mais importantes de Rüsen está no fato de identificar que o saber histórico, se quiser "contribuir para autoafirmação e autocompreensão das crianças e dos jovens ao longo do tempo de suas vidas próprias", depende, em grande parte, do "tratamento comunicativo em sala de aula". Como afirma, "É-lhe necessário desenvolver uma vivacidade que conduza seus destinatários a vê-lo e apropriá-lo como parte de sua vida pessoal” (Rüsen, 2007a, p.30).

Rüsen apresenta aqui a importância dos elementos estéticos inerentes à narrativa histórica e sua função na produção do conhecimento significativo da História.

O termo "estética" exprime, pois, que essa vivacidade possui uma dimensão pré-cognitiva e uma dimensão metacognitiva, nas quais as formas cognitivas e os conteúdos do conhecimento histórico têm de estar enraizados, se sua interpretação do tempo busca ter influência sobre as disposições mentais profundas do agir. (Rüsen, 2007a, p.30) 
É através destes elementos estéticos que

a subjetividade dos destinatários é interpelada no plano em que lida com a força sensorial, simbólica e representativa da relação com o mundo, da autoexpressão e da autocompreensão. Não se trata mais apenas da qualidade literária dos textos historiográficos. A questão está agora na força interpeladora do discurso, na qual, em última instância, também reside a qualidade literária desses textos. (Rüsen, 2007a, p.31)

Sem essa força estética com a qual a subjetividade dos sujeitos é interpelada, a História jamais alcança influência sobre as disposições mentais profundas do agir. É nesse nível estético que as interpretações do passado atuam sobre os alunos de modo a não só reinterpretarem o presente, mas também a se sentirem motivados para o agir. É nesse momento que a consciência histórica atua de modo efetivo, com uma interpretação do passado que produz orientação temporal para o agir humano em sua vida prática. E é também, assim, a partir da força estética da história que podemos compreender o dispositivo com o qual o Estado de Suspensão é instaurado.

\section{O EstAdo DE SUSPENSÃo NA APRENDIZAGEM HISTÓRICA}

Estado de Suspensão é o estado instaurado no momento em que a força interpeladora de um conhecimento provoca, justamente por atingir, de algum modo, o âmago do indivíduo, a suspensão das atribuições de sentido anteriormente em vigor.

É, segundo pensamos, o momento exato em que o conhecimento do passado não simplesmente produz sentido para o presente, mas suspende, ao mesmo tempo, as orientações de sentido anteriormente vigentes. É desse modo que ele é experimentado, vivenciado, como crise, como intensa ruptura na produção de sentido.

É, portanto, um estado de ruptura, de revolução da consciência. A noção de revolução nos parece fundamental por sua oposição à noção de evolução. Só a revolução implica mudança de paradigmas (Kuhn, 1991). Não se trata de um conhecimento que cresce a partir das ideias já estabelecidas. Não se trata de acúmulo de conhecimento e de sentido. Mas, efetivamente, de 
transformação radical do modo de sentir e de pensar a si mesmo e o mundo que nos cerca.

Esse momento, esse estado instaurado, não existe em todo e qualquer processo de aprendizagem, posto que não pode ser reduzido à simples aquisição de novas informações ou novos conceitos. Em uma leitura ou em uma sala de aula, ou mesmo na vivência cotidiana, um conjunto de informações e de conceitos são adquiridos sem que tal Estado de Suspensão seja atingido. Porém, quando uma informação ou um conjunto delas, um conceito ou um conjunto deles, nos arrebata, abala as nossas estruturas sensíveis mais profundas, atinge-nos de tal modo e com tal intensidade que a vida parece perder todo o sentido, ou, ao contrário, ganhar em significação antes jamais vista, só aí cria-se uma cisão entre o que éramos antes e o que seremos depois, e estamos, finalmente, diante desse momento extraordinário.

Tal momento ou estado instaurado durante um processo de aprendizagem não é paulatino, progressivo. Ao contrário, ele é abrupto, repentino e impetuoso. O conhecimento apresenta-se, nessas condições, como uma força que surge intensa e inesperadamente para vascolejar, revirar toda a estrutura mais íntima do sujeito, de modo que, repentinamente, ele se veja diante dessa sensação de arrebatamento diante da qual reage de modo atônito, estupefato.

Não se trata, necessariamente, de uma revolução em todas as atribuições de sentido, mas pode limitar-se a ocorrer em determinados temas da vida humana. Por exemplo, ela pode se dar quando o âmago do sujeito é interpelado por um conhecimento histórico que coloca em suspensão todas as atribuições de sentido anteriormente relacionadas à identidade sexual, de tal modo que o aluno, abruptamente, se veja diante de uma suspeita de tudo o que anteriormente fazia sentido com relação a sua antiga forma de compreensão da sexualidade. De todo modo, ele só pode ocorrer quando houve acesso ao que há de mais profundo nos elementos em que aquele tema produzia sentido. $\mathrm{O}$ Âmago é atingido, o centro mais íntimo do ser. Somente quando o conhecimento histórico consegue alcançar e movimentar o cerne sentimental das definições e valores de um indivíduo é que ele é capaz de instaurar nesse aluno um Estado de Suspensão.

Como estado que só é alcançado graças à força com que acessa a subjetividade dos alunos, o Estado de Suspensão é não só provocado pela força estética inerente à História, mas também é ele mesmo um estado estético. 
Como tal, o Estado de Suspensão pode ser definido com o auxílio de categorias próprias da Estética Filosófica. Quatro elementos próprios da reflexão filosófica moderna sobre Estética nos parecem relevantes para a percepção de nosso conceito.

O primeiro deles diz respeito ao fato de que a estética é, antes de qualquer coisa, uma forma de conhecer. Mais ainda, que essa forma de conhecer implica uma compreensão profunda da existência, da vida, do mundo. A estética não é, assim, mera forma pela qual o conhecimento racional se torna atrativo. Mas, antes, é ela mesma um conhecimento sobre a vida. Como afirma Schopenhauer (2003, p.25): "Consideramos o belo como um conhecimento em nós, um modo todo especial de conhecer, e nos perguntamos que esclarecimentos esse modo de conhecer nos fornece acerca do todo de nossa concepção de mundo".

Admitir, entretanto, que a estética é um modo específico de conhecer nada diz sobre o segundo elemento que para nós será aqui relevante: o caráter metafísico do conhecimento estético.

O que fornece o sentido metafísico desse conhecimento é justamente a possibilidade que ele nos traz de conhecer a vida para além das circunstâncias da própria vida. Isto é, conhecer a vida para além do modo como ela se apresenta no tempo e no espaço. Trata-se assim de ir além do mero fenômeno, da mera pluralidade com a qual o mundo da experiência se apresenta, para alcançar o Uno, o Universal, aquilo que não é simplesmente no aqui e no agora.

Essa possibilidade de trazer o selo do eterno, de nos fazer olhar para a existência em si, para a própria vida enquanto ser, enquanto una, e não enquanto minha vida ou a vida dele, é que fornece ao conhecimento estético o seu caráter metafísico. Nos termos de Schopenhauer (2003, p.26), o conhecimento estético é, antes, "o conhecimento mais profundo e verdadeiro da essência propriamente dita do mundo". Isso porque através da estética alcançamos a Ideia e, por seu intermédio, a Vontade.

Por Ideia, Schopenhauer (2003, p.33) entende a definição platônica de "formas imutáveis, imperecíveis e que nunca devêm de todas as coisas que nascem, mudam e perecem". São assim opostas ao mundo da experiência, que é povoado por "coisas individuais, efêmeras, objetos da experiência" que "não possuem nenhum ser verdadeiro, mas sim um devir e perecer contínuos; por conseguinte, tanto são quanto não são". 
Ao buscar um exemplo para tornar mais clara a sua interpretação da Ideia platônica, Schopenhauer (2003, p.36) nos coloca diante desta imagem:

Pensemos num cavalo diante de nós. Então perguntemos: o que é isso? Platão diria: "Esse animal não possui nenhuma existência verdadeira, mas apenas uma aparente, um constante vir-a-ser, uma existência relativa, que tanto se pode chamar de não ser quanto de ser. Verdadeiramente é apenas a Ideia, que se estampa naquele cavalo, ou cavalo em si mesmo, que não depende de nada, mas é em e para si, nunca veio-a-ser, nunca se extinguindo, mas sempre da mesma maneira. Enquanto reconhecemos nesse cavalo sua Ideia, é por completo indiferente se ele se encontra aqui ou num lugar distante, se ele se oferece desta ou daquela maneira, nesta ou naquela posição, ação, ou se, finalmente, ele é esse ou algum outro cavalo".

A Ideia não é alcançada somente através das obras de artes individuais. Podemos alcançá-la ao nos determos sobre todo e qualquer objeto da própria vida. Para tanto, nos basta que tenhamos os olhos do gênio artístico, a "desvelar-lhe o essencial das coisas" (Schopenhauer, 2003, p.85). Entretanto, a obra de arte facilita o acesso à Ideia. Isso ocorre justamente porque, segundo Schopenhauer (2003, p.85), a vontade individual "constantemente turva nosso conhecer; a parte tomada por nós nas coisas, isto é, o interesse, obsta a concepção pura delas, nosso querer ou não-querer relacionado às coisas presentes atuais faz cair a névoa da subjetividade sobre tudo o que é objetivo".

Assim, impulsionados pela vontade individual, pelo querer, pelo interesse, somos levados a não nos determos sobre as coisas de modo a contemplar as Ideias. Ao contrário, das coisas nos apressamos sobre a sua utilidade. Nos interessa o cavalo enquanto tempo e espaço, não para que eu possa contemplá-lo, mas para me servir dele para chegar mais depressa.

A imagem artística, entretanto, que encontramos por exemplo na pintura, "nos facilita a disposição puramente objetiva já pelo fato de ser uma mera imagem. Pois o que vemos apenas na imagem, ou na poesia, ou num drama excelso, não é para nós efetivo, por consequência se encontra além de qualquer possibilidade de uma relação com nossa vontade" (Schopenhauer, 2003, p.85).

A arte, assim, ao retirar os objetos da sua condição de fenômeno, da sua condição de tempo e lugar determinados, ao transformá-los em Imagem, elimina também qualquer relação de interesse. Não podendo ser consumida, 
utilizada, ela só interessa para nós enquanto representante da ideia, isto é, na sua capacidade de fazer com que os homens acessem não um cavalo no tempo e no espaço, posto que não se trata mais de um cavalo real no tempo e no espaço, mas a Ideia de cavalo, a Ideia, se assim o quisermos, da potência plena de vida.

O Estado de Suspensão, como estado estético, eleva a vida para além das relações e dos valores dominantes no presente. É como se fôssemos efetivamente colocados diante da morte, e tudo o que parecia, até então, urgente, necessário, mas, que não passasse de exigências exclusivas do nosso tempo e lugar (tal como nossos interesses, nosso querer determinado), perdesse em sentido. É com esse olhar para a eternidade, com esse abandono do aqui e do agora, que os seres humanos se elevam em estado estético.

O Estado de Suspensão provocado pela História implica uma ampliação metafísica de significação do mundo. Enquanto uma pessoa vê, em um copo de vidro, a satisfação de sua sede, um ser humano de olhos literários depara com a fragilidade de toda a existência. Assim também se torna o ser humano que tem o seu âmago tocado pela História. Pequenos gestos e atitudes que, de tão rotineiras, não eram sequer notadas, ganham em significação. Porém, tais gestos não valem mais por sua utilidade, tal como o copo de vidro não importa para o estado estético em sua capacidade de segurar a água para matar a sede. Como conhecimentos que eles produzem, são necessariamente desinteressados, como todo e qualquer conhecimento estético (Kant, 1995; Schopenhauer, 2003) e, como gestos, valem como a ocasião externa para a contemplação da Ideia: a fragilidade da existência e, portanto, de nós mesmos.

Eis o que experimenta aquele que se viu em Estado de Suspensão pela História quando, diante de uma cena do Holocausto, estupefato, boquiaberto, experimentava a ruptura de tudo o que anteriormente orientava a sua produção de sentido com relação ao ser humano e aos seus valores inerentes. E ali, por mais que o professor, o filme ou a imagem se referisse a um grupo de judeus específicos, ou a Hitler e a outros personagens históricos, limitados no tempo e no espaço, estava-se diante não simplesmente de uma pessoa concreta de carne e osso, mas da Ideia de Humanidade.

A reflexão de Schopenhauer sobre a História, neste sentido, é bastante reveladora. Ao se referir ao que chamou de história do gênero humano, afirma que "os eventos do mundo possuem significação só na medida em que são as 
letras a partir das quais se pode ler a Ideia do homem, e não em e por si mesmos" (Schopenhauer, 2005, p.251). Apesar de Schopenhauer perceber que a História, ao se debruçar sobre os eventos e atores limitados no tempo e no espaço, não é jamais um modo de conhecer metafísico (tal como todas as demais ciências, que só estabelecem as relações entre os fenômenos), um conhecimento da essência da coisa em si, podemos perceber nesse trecho que ele reconhece a possibilidade de a História trazer determinados eventos do mundo, como as letras que expressam a Ideia.

Embora Schopenhauer jamais tenha dito isso, é possível pensar a história do mesmo modo como ele pensou as demais obras de arte. Quando estamos diante de Cleópatra, Júlio César ou de qualquer outro personagem ou evento histórico narrado pelo historiador, não estamos diante de homens concretos, mas de uma imagem; para ser mais exato, de uma reconstrução linguística-literária. Nesse sentido, não estamos diante de algo efetivo, de algo que possa ser tomado com interesse. Não podemos, desse modo, nos deitar com Cleópatra, assim como não podemos devorar as frutas do Natureza-morta com cesta de frutas de Paul Cézanne. O ser humano do passado, transformado em personagem histórico pela narrativa do historiador, pode ser tão exemplar da Ideia do Homem quanto o ser humano de uma pintura.

É assim também que a própria História pode facilitar o acesso à Ideia e, por conseguinte, a criação de um Estado de Suspensão. O acesso à Ideia precisa, entretanto, ser compreendido em acordo com a concepção de coisa em si em Schopenhauer. Aquilo que é eternamente a própria coisa em si, não é efetivamente a Ideia, mas a Vontade. Esta, a coisa em si propriamente dita, deixa um rastro de sua existência nas Ideias. É por esse rastro que o conhecimento estético pode sentir a presença da própria Vontade. $\mathrm{Na}$ Ideia de Homem que acessamos ao nos determos sobre uma imagem do Holocausto, podemos intuir a própria coisa em si: a vontade incessante que carregamos em nós, e que sentimos em cada um dos movimentos do nosso próprio corpo, e que também é a coisa em si de todos os objetos do mundo, tenham eles a forma vegetal, animal, mineral ou qualquer outra forma fenomênica.

Por último, é preciso avaliar o terceiro elemento da estética filosófica que nos interessa para o nosso conceito fundamental. As duas categorias fundamentais da Estética Filosófica podem ser tomadas de empréstimo para uma teoria da aprendizagem. Porém, entre as duas categorias fundamentais da 
estética filosófica moderna, o Belo e o Sublime, somente a segunda delas é capaz de expressar esse estado estético da aprendizagem. Isso porque o Belo alegra, mas não arrebata, não aterroriza, não nos coloca diante da grandiosidade do mundo.

Como afirmou Edmund Burke (1993), tendo sido depois endossado por Kant (1993) e por Schopenhauer (2003): "Tudo que seja de algum modo capaz de incitar as ideias de dor e de perigo, isto é, tudo que seja de alguma maneira terrível ou relacionado a objetos terríveis ou atua de um modo análogo ao terror constitui uma fonte do sublime, isto é, produz a mais forte emoção de que o espírito é capaz" (Burke, 1993, p.48).

O Estado de Suspensão é um Estado Sublime na medida em que o aluno não se coloca diante dele com um sorriso no rosto, mas embasbacado, estupefato, atônito. Como afirma Schopenhauer (2003), o sublime é o estado que se instaura em situações em que as figuras contempladas nos colocam diante da hostilidade do mundo:

pode ocorrer que precisamente os objetos que nos convidam com suas figuras significativas para sua pura contemplação possuam uma relação hostil com a Vontade humana em geral, tal qual ela se expõe em sua objetividade, o corpo humano. E isso é possível de duas maneiras: ou eles lhe podem ser adversos mediante a exibição de um poder que suprimiria qualquer resistência, portanto, um poder ameaçador; e esse tipo nomeia com a expressão kantiana, sublime dinâmico; ou também a grandeza dos objetos é incomensurável e diante deles o corpo humano é reduzido a nada, tendo-se aí o sublime matemático. (Schopenhauer, 2003, p.104)

Schopenhauer percebeu que a contemplação da história e do espaço tem a capacidade de produzir o sentimento Sublime.

Quando nos perdemos na consideração da grandeza infinita do mundo no espaço e no tempo; quando meditamos nos séculos passados e por virem; ou também quando consideramos o céu noturno estrelado, tendo inumeráveis mundos efetivamente diante dos olhos, e a incomensurabilidade do mundo no espaço e no tempo se impõe à nossa consciência, sentimo-nos reduzidos a nada, sentimo-nos como indivíduo, como corpo vivo, como fenômeno transitório da Vontade, uma gota no oceano, condenados a desaparecer, a dissolver-nos no nada. (Schopenhauer, 2003, p.110) 
A contemplação da grandeza infinita da experiência humana no tempo implica contemplação da ideia de fragilidade de toda a existência. O temor que tal grandeza produz diante de nossa tão frágil e pequena existência e, ao mesmo tempo, o fato de estarmos diante da História e, portanto, estarmos a salvo de seu passado, é o que possibilita a produção do sentimento Sublime.

Desse modo, o Estado de Suspensão como Estado Estético Sublime implica um estado de revolução da consciência histórica. Alcançá-lo, buscar os meios em que ele possa ser produzido, tentar criar as condições para que, nas aulas de história, os alunos sejam interpelados de algum modo por uma força estética do conhecimento histórico que seja capaz de deixá-los boquiabertos, atônitos, estupefatos, talvez precise se tornar uma das preocupações principais dos professores de história.

Obviamente, o Estado de Suspensão, primeiramente, não pode ser entendido como voluntarismo do professor, como se ele conseguisse produzi-lo nos alunos sem levar em consideração a disposição interna formulada no interior do universo cultural dos próprios alunos. Não se trata de um estado que é transmitido de uma consciência para outra. Em segundo lugar, o Estado de Suspensão implica não apenas uma revolução positiva na consciência histórica dos alunos, mas, como o próprio nome diz, um momento de suspensão, um momento de crise, que não pode ser estimulado sem a consciência profunda também de todos os seus possíveis efeitos devastadores.

\section{REFERÊNCIAS}

BAROM, Wilian Carlos Cipriani. Didática da História e Consciência Histórica: pesquisas na pós-graduação (2001-2009). Dissertação (Mestrado em Educação) Programa de Pós-Graduação em Educação, Universidade Estadual de Ponta Grossa (UEPG). Ponta Grossa, 2012.

BERGMANN, Klaus. A história na reflexão didática. Revista Brasileira de História, São Paulo, v.9, n.19, p.29-42, 1990.

BORRIES, Bodo von. Competência do pensamento histórico, domínio de um panorama histórico, ou conhecimento do cânone histórico? Revista de Educação Histórica, Curitiba, n.1, p.155-178, 2012.

BURKE, Edmund. Uma investigação Filosófica sobre a Origem de nossas Ideias do Sublime e do Belo. Trad. Enid Abreu Dobránszky. Campinas, SP: Papirus, 1993. 
CARDOSO, Oldimar. Para uma definição de didática da história. Revista Brasileira de História, São Paulo, v.28, n.55, p.153-170, 2008.

CERRI, Luís Fernando. Didática da história: uma leitura teórica sobre a história na prática. Revista de História Regional, Ponta Grossa: Ed. UEPG, v.15, n.2, p.264278, 2010.

KANT, Emmanuel. Crítica da faculdade do juízo. Trad. Valério Rohden e Antonio Marques. 2.ed. Rio de Janeiro: Forense Universitária, 1995.

. Observações sobre o sentimento do belo e do sublime; Ensaio sobre as doenças mentais. Trad. Vinícius de Figueiredo. Campinas, SP: Papirus, 1993.

KUHN, Thomas S. A estrutura das revoluções científicas. São Paulo: Perspectiva, 1991.

LEE, Peter. Progressão da compreensão dos alunos em História. In: BARCA, Isabel. Perspectivas em Educação Histórica. Braga: Universidade do Minho, 2001.

OLIVEIRA, Thiago A. D. de. A relação ensino e aprendizagem como práxis: a educação histórica e a formação de professores. Dissertação (Mestrado em Educação) - Universidade Federal do Paraná. Curitiba, 2012.

OLIVEIRA, Thiago; SCHMIDT, Maria Auxiliadora. Protonarrativas e Possibilidades de Intervenção: práxis e educação histórica em um estudo no IFPR (Campus Curitiba). Revista História e Diversidade, Cuiabá, v.4, n.1, p.189-202, 2014.

RÜSEN, Jörn. Aprendizagem histórica: fundamentos e paradigmas. Trad. Caio C. Pereira, Daniel Martineschen, Peter H. Rautman e Sibele Paulino. Curitiba: W. A. Editores, 2012.

. Cultura faz sentido: orientações entre o ontem e o amanhã. Trad. Nélio Schneider. Petrópolis, RJ: Vozes, 2014.

. Didática da história: passado, presente e perspectivas a partir do caso alemão. Práxis Educativa, Ponta Grossa, PR, v.1, n.2, p.7-16, 2006.

. História viva. Trad. Estevão de Rezende Martins. Brasília: Ed. UnB, 2007a.

. Razão histórica. Trad. Estevão de Rezende Martins. Brasília: Ed. UnB, 2001.

. Reconstrução do passado. Trad. Asta-Rose Alcaide. Brasília: Ed. UnB, 2007.

. Teoria da História: uma teoria da história como ciência. Trad. Estevão de Rezende Martins. Curitiba: Ed. UFPR, 2015.

SADDI, Rafael. Didática da História na Alemanha e no Brasil: considerações sobre o ambiente de surgimento da NEU GESCHICHTSDIDAKTIK na Alemanha e os desafios da nova didática da história no Brasil. OPSIS, Catalão, GO, v.14, n.2, p.133147, 2014.

. O parafuso da didática da história. Acta Scientiarum. Education, Maringá, PR, v.34, n.2, p.211-220, 2012. 
SCHOPENHAUER, Arthur. A Metafísica do Belo. Trad. Jair Barbosa. São Paulo: Ed. Unesp, 2003.

. O Mundo como Vontade e como Representação, tomo 1. Trad. Jair Barbosa. São Paulo: Ed. Unesp, 2005.

\section{NOTAS}

${ }^{1}$ Por "textos programáticos" nos referimos a artigos teóricos de autores brasileiros que refletiram sobre o campo da didática da história tendo como referência a Geschichtsdidaktik, tais como: CARDOSO (2008), CERRI (2010) e SADDI (2014; 2012).

${ }^{2}$ Para um balanço das teses e dissertações da área de ensino de história no Brasil que tomam como referência o pensamento de Jörn Rüsen, ver a dissertação de mestrado de Wilian Barom (2012), intitulada Didática da História e Consciência Histórica: pesquisas na pós-graduação brasileira (2001-2009).

${ }^{3}$ Sobre a History Education e a definição de conceitos epistemológicos, ver Peter Lee (2001).

Artigo recebido em 2 de abril de 2016. Aprovado em 1 de junho de 2016. 